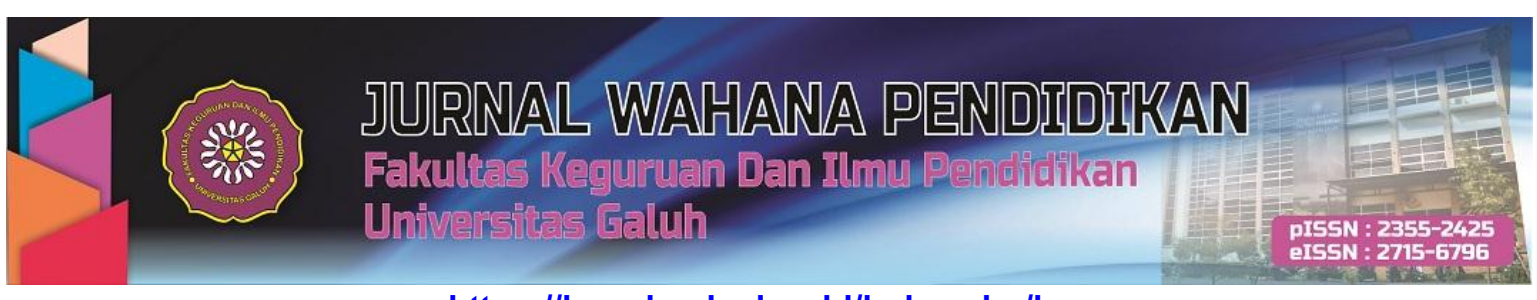

https://jurnal.unigal.ac.id/index.php/jwp

\title{
PENGARUH LATIHAN INTERVAL TRAINING DENGAN RUNNING CIRCUIT TERHADAP PENINGKATAN VO2 MAX
}

\author{
Hendra Rustiawan ${ }^{1}$ \\ Program Studi Pendidikan Jasmani \\ 1 Universitas Galuh, JI. R. E. Martadinata No.150, Ciamis, Indonesia \\ Email: hendra6610111972@gmail.com
}

\begin{abstract}
This study aims to determine how much the influence of the interval training and running circuit training has onVo2 Max improvement. As the objectives of the study, the author used a pre-experiment method by means of the Pre Test Post Test Experiment Design. The population of this research was the 20 students of the Running Loka Ciamis Community. The research instrument used to collect the data was a Bleep test. Based on the data analysis using SPSS series 24, the results of data showed as follows:1. There was a significant effect of the interval training process on increasingVo2 Max with a probability value (sig.) Of $0.000<0.05,2$. There was a significant effect of the running circuit training process on increasingVo2 Max with a probability value (sig.) $0.015<0.05$, 3. There was a significant difference between the Interval Training group and the Running Circuit. Conclusions of the results of the study: 1 . Interval training exercises have a significant effect on increasingVo2 Max in the running community, 2. Running circuit training has a significant influence on the increase ofVo2 Max in the running community, 3. There was a significant difference between interval training and running circuit training to increaseVo2 Max in the running community. It is Expected that interval training with the running circuit can be used as training material for physical conditions on cardiovascular endurance.
\end{abstract}

Keywords: Interval Training, Running Circuit,Vo2 Max.

\section{ABSTRAK}

Penelitian ini bertujuan untuk menganalisis pengaruh latihan interval training dengan latihan running circuit terhadap peningkatan Vo2 Max. Sesuai dengan tujuan penelitian di atas, maka penulis menggunakan metode eksperimen dengan "Pre Test Post Test Experiment Design". Populasi penelitian ini adalah siswa komunitas Running Loka Kabupaten Ciamis yang berjumlah sebanyak 20 orang. Instrumen penelitian yang digunakan untuk mengumpulkan data adalah tes koordinasi lempar tangkap bola. Berdasarkan analisis data menggunakan SPSS serie 22, hasil pengolahan data adalah sebagai berikut : 1. Terdapat pengaruh yang signifikan dari proses latihan interval training terhadap peningkatanVo2 Max dengan nilai probabilitas (sig.) $0.000<0.05$ sehingga dapat disimpulkan Latihan interval training memberikan pengaruh yang signifikan terhadap peningkatanVo2 Max pada komunitas lari running loka Kabupaten Ciamis, 2. Terdapat pengaruh yang signifikan dari proses latihan running circuit terhadap peningkatanVo2 Max dengan nilai probabilitas (sig.) $0.015<0.05$ sehingga dapat disimpulkan Latihan running circuit memberikan pengaruh yang signifikan terhadap peningkatanVo2 Max pada komunitas lari running loka Kabupaten Ciamis, 3. Terdapat perbedaan yang signifikan antara kelompok latihan Interval Training dengan Running Circuit sehingga dapat disimpulan hasil Terdapat perbedaan yang signifikan antara latihan interval training dengan latihan running circuit terhadap peningkatan Vo2 Max pada komunitas lari running loka Kabupaten Ciamis. Diharapkan sebagai salah satu pertimbangan bentuk latihan interval training dengan running circuit dapat dijadikan alternative bahan latihan kondisi fisik pada komponen daya tahan umum/kardiovaskular.

Kata Kunci: Interval Training, Running Circuit,Vo2 Max.

Cara sitasi:

Rustiawan, H (2020). Pengaruh Latihan Interval Training dengan Running Circuit terhadap Peningkatan Vo2 Max . Jurnal Wahana Pendidikan, 7 (1), 15-28.

Sejarah Artikel:

dikirim desember 2019, direvisi januari 2020, diterima januari 2020 


\section{PENDAHULUAN}

Pengaruh olahraga sudah mulai terasa di tahun-tahun ini. Wadah olahraga tidak hanya ada dan tercatat secara resmi di pemerintah terutama di KONI, namun masyarakat yang peduli terhadap kesehatan sudah mulai membuat komunitas-komunitas olahraga sesuai dengan olahraga yang digemari. Salah satu contoh adanya komunitas lari jarak jauh atau yang biasa disebut marathon di Kabupaten Ciamis yaitu "Running loka." Komunitas ini lebih banyak menggunakan track atau jalur jalan yang berasapal, bisa di jalan raya atau jalan pedesaan disekitar Kabupaten Ciamis dan jarang sekali menggunakan stadion atletik. Pelari yang tergabung dalam komunitas running loka adalah usia-usia muda bahkan ada juga yang masih duduk di bangku SMA. Hal ini menandakan bahwa memiliki gaya hidup aktif masih ada di kalangan usia muda di Kabupaten Ciamis, sedangkan zaman sekarang ini banyak kalangan muda bahkan remaja yang sudah terbawa arus dengan tren gadget yang mendominasi pola hidup yang tidak sehat. (Bădicu \& Lorand Balint, 2016). Dengan memiliki motivasi dalam menjalankan gaya hidup aktif dengan olahraga dapat memiliki tubuh yang sehat dan terhindar dari berbagai penyakit adalah salah satu tujuan dari komunitas "running loka". (Durstine, Gordon, Wang, \& Luo, 2015)

Melakukan aktivitas fisik dalam hal ini adalah olahraga, harus dilakukan secara teratur yaitu sebuah intensitas yang sesuai, durasi dan frekuensi yang teratur. Intensitas olahraga harus semakin meningkat seiring seiring meningkatkan kinerja utuk mencapai hasil yang optimal (Rustiawan, Sugiawardan, \& Nurzaman, 2019). Namun, beban kerja atau olahraganya harus tetap berhubungan dengan kebugaran dan kekuatan individu. Olahraga yang teratur akan membuat penurunan terhadap resting heart rate, meningkatkan ukuran jantung, dan dinding jantung. Salah satu olahraga yang dapat meningkatkan kerja jantung dan paru-paru menjadi maksimal adalah dengan melakukan jenis olahraga aerobik, karena hubungannya dengan kebugaran aerobik yaitu pemanfaatan oksigen yang disalurkan ke seluruh tubuh secara maksimal.(Cheng, Chiu, \& Su, 2019) Selanjutnya adalah hubungan antara lari dengan kapasitas tubuh dalam menyerap oksigen melalui kerja jantung dan paru-paru atau yang biasa di sebutVo2 Max. Sejumlah penelitian menunjukan bahwa meningkatkan VO2 max dapat dengan latihan pada intensitas detak jantung 65\% sampai $85 \%$ dari detak jantung maksimum, selama setidaknya 20 menit, frekuensi 3-5 kali seminggu. (Scribbans, Vecsey, Hankinson, Foster, \& Gurd, 2016). Contoh latihan yang dapat dilakukan adalah lari diselingi jogging jarak jauh, fartlek, circuit training, cross country, interval training, atau kombinasi dan modifikasi dari latihan tersebut.

Salah satu unsur kebugaran jasmani yang sangat penting adalah daya tahan. Dengan daya tahan yang baik, performa atlet akan tetap optimal dari waktu ke waktu karena memiliki waktu menuju kelelahan yang cukup panjang. Hal ini berarti bahwa atlet mampu melakukan gerakan, yang dapat dikatakan, berkualitas tetap tinggi sejak awal hingga akhir pertandingan. Endurance atau daya tahan adalah kemampuan seseorang melaksanakan gerak dengan seluruh tubuhnya dalam waktu yang cukup lama dan dengan tempo sedang sampai cepat tanpa mengalami rasa sakit dan kelelahan berat (Morici et al., 2016). Kemampuan otot untuk melakukan kerja terus-menerus adalah sangat penting dalam aktivitas olahraga karena secara tidak langsung merupakan daya untuk dapat mengatasi kelelahan otot. Latihan daya tahan atau endurance dapat dibagi menjadi dua macam. Daya tahan merupakan salah satu komponen biomotorik utama/dasar dalam setiap cabang olahraga. Komponen biomotor daya tahan pada umumnya digunakan sebagai tolok ukur untuk mengetahui tingkat kebugaran jasmani (physical fitness) olahragawan (Junaidi, 2018). Berdasarkan dua pengertian tersebut maka daya tahan didefinisikan sebagai kemampuan organ tubuh untuk melawan kelelahan selama berlangsungnya aktivitas olahraga atau kerja.

Daya tahan terbagi menjadi dua yaitu daya tahan umum dan daya tahan khusus (Armstrong, 2011). Daya tahan Aerobik adalah aktivitas yang memerlukan bantuan oksigen (O2). Anaerobik adalah aktivitas yang tidak memerlukan bantuan oksigen. Anaerobik laktik cirinya selama aktivitas berlangsung menghasilkan asam laktat, sedang yang alaktik tidak menghasilkan asam laktat selama berlangsung aktivitas. Daya tahan aerobik adalah kemampuan seseorang untuk mengatasi beban 
latihan dalam jangka waktu lebih dari 3 (tiga) menit secara terus menerus. Daya tahan anaerobik laktik adalah kemampuan seseorang untuk mengatasi beban latihan dengan intensitas maksimal dalam jangka waktu antara 10 detik sampai 120 detik. Sedang daya tahan anaerobik alaktik adalah kemampuan seseorang untuk mengatasi beban latihan dengan intensitas maksimal dalam jangka waktu kurang dari 10 detik.

\section{Daya Tahan Umum}

Daya tahan umum merupakan kemampuan tubuh untuk melakukan kegiatan atau pekerjaan dalam waktu lama tanpa mengalami kelelahan yang berarti (Lambert, Viljoen, Bosch, Pearce, \& Sayers, 2005) Daya tahan termasuk salah satu komponen penting dalam aspek kebugaran jasmani. Banyak orang yang melakukan olahraga dengan tujuan untuk meningkatkan daya tahan tubuh (Tanja C. Roy, Barbara A. Springer, Vancil McNult, 2010). Daya tahan jantung dan paru-paru atau general endurance dapat ditingkatkan melalui latihan yang berlangsung pada jarak yang jauh dan waktu yang cukup lama (Hottenrott, Ludyga, \& Schulze, 2012) seperti naik ke puncak gunung, lintas alam (cross country), renang jarak jauh (long swimming), dan lari jarak jauh (long running) (Olstad, Bjørlykke, \& Olstad, 2019).

Pengertian daya tahan ditinjau dari kerja otot adalah kemampuan kerja otot atau sekelompok otot dalam jangka waktu tertentu (Bird, Bird, Tarpenning, \& Marino, 2005) sedang pengertian daya dari sistem energi adalah kemampuan kerja organ-organ tubuh dalam jangka waktu tertentu. Istilah daya tahan dalam dunia olahraga dikenal sebagai kemampuan organ tubuh olahragawan untuk melawan kelelahan selama berlangsungnya aktivitas atau kerja (Pageaux \& Lepers, 2018). Latihan daya tahan dipengaruhi dan berdampak pada kualitas sistem kardiovaskular, pernapasan dan sistem peredaran darah (Nystoriak \& Bhatnagar, 2018). Oleh karana itu faktor yang berpengaruh terhadap daya tahan adalah kemampuan maksimal dalam memenuhi komsumsi oksigen yang biasa di kenal dengan istilah Vo2 Max (Bruno, Smirmaul, Bertucci, \& Inaian, 2013).

Komponen biomotorik daya tahan pada umumnya digunakan sebagai salah satu tolak ukur untuk mengetahui tingkat kebugaran jasmani (physical fitness) atlet (Tirtawirya, 2019). Kebugaran jasmani adalah suatu keadaaan kemampuan peralatan tubuh yang dapat memelihara keseimbangan tersedianya energi sebelum, selama, dan sesudah aktivitas kerja berlangsung (WHO, 2018). Hubungan antara daya tahan dan kinerja (penampilan) fisik atlet (Firmansyah, 2017) diantaranya adalah

1. Kemampuan untuk melakukan aktivitas kerja secara terus menerus dengan intensitas yang tinggi dan dalam jangka waktu lama.

2. Kemampuan untuk memperpendek waktu pemulihan (recovery), terutama pada cabang olahraga pertandingan dan permainan.

3. Kemampuan untuk menerima beban latihan yang lebih berat, lebih lama, dan bervariasi.

Dengan demikian atlet yang memiliki daya tahan yang baik akan mendapatkan keuntungan selama bertanding (Rahmad, 2016), diantaranya, mampu:

1. Menentukan irama dan pola permainan dalam olahraga.

2. Memelihara atau mengubah irama dan pola permainan sesuai yang diinginkan, dan.

3. Berjuang secara ulet dan tidak mudah menyerah selama bertanding.

\section{Vo2max}

Volume $\mathrm{O} 2$ max ini adalah suatu tingkatan kemampuan tubuh yang dinyatakan dalam liter per menit atau milliliter/menit/kg berat badan (Cade et al., 2018). Setiap sel dalam tubuh manusia membutuhkan oksigen untuk mengubah makanan menjadi ATP (adenosine triphosphate) (Salin, Auer, Rey, Selman, \& Metcalfe, 2015) yang siap dipakai untuk kerja tiap sel yang paling sedikit mengkonsumsi oksigen adalah otot dalam keadaan istirahat. Sel otot yang berkontraksi membutuhkan 8 banyak ATP. Akibatnya otot yang dipakai dalam latihan membutuhkan lebih banyak oksigen dan menghasilkan CO2 (Gunawan, Millah, \& Hartadji, 2017).

Untuk melatih VO2 max, ada beberapa hal yang harus diperhatikan, latihan harus menggunakan otot-otot besar tubuh secara intensif (terus-menerus) dalam durasi yang relatif lama 
(Astuti, 2019). Latihan yang baik untuk meningkatkanVo2 Max adalah jenis latihan cardio atau aerobik, latihan yang memacu detak jantung, paru dan sistem otot (Hulke \& Phatak, 2015) Latihan harus berlangsung dalam durasi yang relatif lama namun dengan intensitas sedang (Cheng et al., 2019). Sejumlah penelitian menunjukan bahwa meningkatkanVo2 Max dapat dengan latihan pada intensitas detak jantung $65 \%$ sampai $85 \%$ dari detak jantung maksimum , selama setidaknya 20 menit, frekuensi 3-5 kali seminggu dari French \& long (2012:56). Contoh latihan yang dapat dilakukan adalah lari diselingi jogging jarak jauh, fartlek, circuit training, cross country, interval training, atau kombinasi dan modifikasi dari latihan tersebut.

Berdasarkan latar belakang dan teori di atas penulis memiliki ide untuk dijadikan bahan penelitian pada pelari komunitas "running loka" pada kapasitas kemampuan penyerapan oksigen untuk tubuh secara maksimal dari rutinitas olahraga lari yang dilakukan. Untuk itu penulis mengajukan judul penelitian adalah, "Pengaruh Latihan Interval Training 10/30 dengan running circuit Terhadap PeningkatanVo2 Max."

Penelitian selayaknya memiliki tujuan agar penelitiannya terpokus pada satu bidang kajian saja. Berdasarkan latar belakang dan rumusan masalah penelitian tujuan penelitian yang akan diuraikan adalah :

1. Untuk mengetahui latihan interval training memberikan pengaruh yang signifikan terhadap peningkatan Vo2 Max

2. Untuk mengetahui latihan running circuit memberikan pengaruh yang signifikan terhadap peningkatan Vo2 Max.

3. Untuk mengetahui perbedaan yang signifikan antara latihan interval training dengan running circuit circuit terhadap peningkatan Vo2 Max.

\section{METODE PENELITIAN}

Metode penelitian yang digunakan adalah metode eksperimen, yaitu salah satu metode yang digunakan sebagai panduan dalam melakukan penelitian, seberapa besar hubungan sebab akibat antara variabel bebas dengan variabel terikat (Igwenagu, 2016) Penulis menggunakan metode ini karena sesuai dengan penelitian yang akan dilaksanakan, yaitu untuk mencari seberapa besar sebab akibat dari latihan interval training dan running circuit terhadap peningkatanVo2 Max. Desain penelitian yang digunakan adalah two group pretest posttest design. Populasi yang digunakan adalah Komunitas Running Loka Kabupaten Ciamis yang berjumlah 20 orang putra. Jumlah instrumen yang akan digunakan untuk penelitian akan tergantung pada jumlah variabel yang diteliti. Bila variabel penelitiannya dengan jumlah yang sama, maka jumlah instrumen yang digunakan untuk penelitian pun sama juga. Instrumen-instrumen penelitian sudah ada yang dibakukan, tetapi masih ada yang harus melalui uji instrument terlebih dahulu (Alwan, Menza Hendri, 2017). Karena instrumen penelitian akan digunakan untuk melakukan pengukuran dengan tujuan menghasilkan data kuantitatif yang valid dan reliabel. Instrumen yang digunakan dalam penelitian ini adalah Bleep test dari Bleep tes atau kata lainnya multistage fitness $20 \mathrm{~m}$ test (Paradisis, Zacharogiannis, Mandila, \& Smirtiotou, 2014) merupakan tes berlari terus menerus di antara dua garis yang berjarak $20 \mathrm{~m}$ selama terdengar suara beep yang sudah direkam, tes ini merupakan salah satu tes yang digunakan untuk mengukur prediksi kekutan aerobik maksimal atau Vo2 Max (Lugina Aditia , Badruzaman, Sandey Tantra Paramitha, 2018).

Teknik pengumpulan data dalam penelitian ini adalah hasil balikan (shuttle) sesuai kemampuan partisipan. Proses penelitian diawali memberikan pemanasan kepada siswa. Setelah diberikan petunjuk bagaimana melakukan tes denyut nadi agar siswa paham pelaksanaan tes tidak terjadi kesalahan. Alat-alat yang digunakan dalam tes denyut nadi adalah Lapangan olahraga, Pluit, Stopwatch., Blangko penilaian, CD, Alat-alat tulis.

Adapun cara pelaksanaan adalah seorang tester melakukan berlari terus menerus diantara 2 garis berjarak $20 \mathrm{~m}$, setelah aba aba start dimulai mengikuti suara beep yang sudah di rekam di dalam CD atau Software. Hal ini akan berlangsung mengikuti aturan waktu yang sudah ditentukan 
oleh para ahli, Bila atlet belum mencapai garis pada waktu terdengar suara beep, dia harus menyelesaikannya dahulu baru kemudian berbalik dan berusaha menyesuaikan kecepatan larinya di antara dua beep, Apabila Atlet sudah mencapai garis sebelum terdengar beep, dia harus menunggu sampai terdengar beep, Tes dihentikan bila tester dua kali gagal mencapai garis (kurang dari 2 meter) pada saat pembalikan dua kali berturut-turut, Waktu antara beep memendek setiap menit (level). Berikut gambar pelaksanaan Bleep test.

Pada level 1 dinyatakan bahwa untuk balikannya (suttlte) adalah 7 kali balikan dengan akumulasi balikan selama 7 kali , kecepatan $8.0 \mathrm{~km} / \mathrm{h}$ dan waktu balikan adalah 9.00 detik dengan waktu total level adalah 63 detik. Jarak yang ditempuh yaitu 140 meter dengan akumulasi 140 meter dan total waktu keseluruhan di level 1 adalah 1.03 detik (Fajar Agni Fauzan, Agus Rusdiana, 2016) begitu juga dengan level yang lainnya. Data tabel diatas inilah yang akan menentukan penilaian terhadap atlet atau tester yang melakukan bleep tes yang nantinya akan dikonversikan kedalam nilai perkiraanVo2 Max. Nilai atlet atau tester ditunjukkan dengan level dan jumlah lari bolak-balik yang dicapai sebelum mereka gagal menyesuaikan dengan rekaman beep. Nilai ini bisa dikonversikan ke dalam 'VO2max equivalent score' dengan menggunakan rumus yang akan dibahas selanjutnya. Selanjutnya hasil dari Bleep test tersebut dimasukan pada tabel norma-norma Bleep test

\section{HASIL DAN PEMBAHASAN}

Berdasarkan data hasil penelitian di lapangan yang selanjutnya akan diteruskan dengan melakukan pengolahan data. Untuk memudahkan pengolahan data pada pembahasan penelitian ini menggunakan statistika SPSS 24. Pengolahan ini sudah biasa digunakan dalam setiap penelitian terutama pada penelitian ini. Kegiatan penelitian ini dibagi menjadi beberapa tahap, yaitu deskripsi data, hasil uji normalitas data, hasil uji homogenitas, dan hasil uji dua rata-rata dengan uji-t (Everitt, Sabine Landau, 2004). Untuk uji-t disajikan dengan dua pengujian, yaitu paired sample t-test dan independent sample test digunakan untuk mengetahui perbedaan dua rata-rata selisih dua kelompok penelitian tersebut (Arkkelin, 2014)

Deskripsi data menyajikan hasil pengolahan data secara deskriptif yang disajikan dalam bentuk tabel dan grafik diagram.

Tabel 1.

Data Tes Awal Bleep test Kelompok Interval Training dan Running Circuit

\begin{tabular}{ccccccc}
\hline Kelompok Sampel & N & $\begin{array}{c}\text { Rata- } \\
\text { rata }\end{array}$ & $\begin{array}{c}\text { Standard } \\
\text { Deviasi }\end{array}$ & Varians & $\begin{array}{c}\text { Skor } \\
\text { Terendah }\end{array}$ & $\begin{array}{c}\text { Skor } \\
\text { Tertinggi }\end{array}$ \\
\hline Interval training & 10 & 36.22 & 7.66 & 58.80 & 26.80 & 46.80 \\
Running circuit & 10 & 38.74 & 7.30 & 53.31 & 27.10 & 49.40
\end{tabular}

Dari tabel 1 dapat diketahui nilai rata-rata tes awal kelompok latihan interval taining adalah 36.22 dengan standar deviasi 7.66 dan varians 58.80 Sedangkan skor terendah interval taining adalah 26.80 sedangkan skor interval taining tertingginya adalah 46.80 . Nilai rata-rata tes awal untuk kelompok latihan running circuit adalah 38.74 dengan standar deviasi 7.30 dan varians 27.10 Skor running circuit adalah 4 sedangkan skor running circuit terendah tertingginya adalah 49.40 .

Tabel 2.

Data Tes Akhir Bleep test Kelompok Interval Training dan Running Circuit

\begin{tabular}{ccccccc}
\hline $\begin{array}{c}\text { Kelompok } \\
\text { Sampel }\end{array}$ & N & $\begin{array}{c}\text { Rata- } \\
\text { rata }\end{array}$ & $\begin{array}{c}\text { Standard } \\
\text { Deviasi }\end{array}$ & Varians & $\begin{array}{c}\text { Skor } \\
\text { Terendah }\end{array}$ & $\begin{array}{c}\text { Skor } \\
\text { Tertinggi }\end{array}$ \\
\hline Interval training & 10 & 38.05 & 7.55 & 57.06 & 27.50 & 48.30 \\
Running circuit & 10 & 39.94 & 7.69 & 59.27 & 29.40 & 49.80 \\
\hline
\end{tabular}

Dari tabel 2 dapat diketahui nilai rata-rata tes akhir kelompok latihan interval training adalah 38.05 dengan standar deviasi 7.55 dan varians 57.06 Sedangkan skor interval training yang terendah adalah 27.50 sedangkan skor interval training tertingginya adalah 48.30 . Nilai rata-rata tes akhir untuk kelompok latihan skor running circuit adalah 39.94 dengan standar deviasi 7.69 dan varians 59.40. Skor latihan skor running circuit terendah adalah 29.40 sedangkan skor running circuit tertingginya adalah 49.80.Terlihat bahwa adanya peningkatan berdasarkan tes awal dengan 
tes akhir sehingga penulis beranggapan bahwa adanya peningkatan secara signifikan meskipun secara sementara karena hanya berdasarkan deskripsi data saja.

\section{Uji Normalitas}

Uji normalitas dilakukan untuk mengetahui apakah data berada pada taraf distribusi normal atau tidak (Machali, 2016). Selain itu, uji normalitas juga menentukan langkah selanjutnya uji statistik yang akan digunakan antara parametric dan nonparametrik. Apabila data tersebut berdistribusi normal dan homogen maka pengujiannya dengan statistik parametrik, namun apabila data tersebut berdistribusi tidak normal atau tidak homogen maka pengolahan statistiknya dengan statistik nonparametric (Everitt, Sabine Landau, 2004).

Tabel 3.

Uji Normalitas Tes Awal Kelompok Interval Training dan Running Circuit

\begin{tabular}{cccc}
\hline \multirow{2}{*}{ Kelompok } & \multicolumn{3}{c}{ Shapiro-Wilk } \\
& Statistik & df & Sig \\
\hline Tes Awal & & & \\
Kel. lat. Interval training & 0.908 & 10 & 0.268 \\
Kel. lat.Running circuit & 0.947 & 10 & 0.638 \\
\hline
\end{tabular}

Kriteria Keputusan :

1. Nilai Sig. atau probabilitas $<0.05$ (Distribusi tidak normal)

2. Nilai Sig. atau probabilitas $>0.05$ ( Distribusi Normal)

Tes awal

1. Kelompok latihan: Interval training Sig. $0.268>0.05$ (Distribusi Normal)

2. Kelompok latihan : Running circuit : Sig. $0.638>0.05$ ((Distribusi Normal

Tabel 4.

Uji Normalitas Tes Akhir Kelompok Interval Training dan Running Circuit

\begin{tabular}{cccc}
\hline \multicolumn{1}{c}{ Kelompok } & \multicolumn{3}{c}{ Shapiro-Wilk } \\
& Statistik & df & Sig \\
\hline Tes Akhir & & & \\
Kel. lat. Interval training & 0.905 & 10 & 0.249 \\
Kel. lat.Running circuit & 0.940 & 10 & 0.550 \\
\hline
\end{tabular}

Kriteria Keputusan :

1. Nilai Sig. atau probabilitas $<0.05$ (Distribusi tidak normal)

2. Nilai Sig. atau probabilitas $>0.05$ ( Distribusi Normal)

Tes akhir

1. Kelompok latihan: Interval training Sig. $0.249>0.05$ (Distribusi Normal)

2. Kelompok latihan: Running circuit : Sig. $0.550>0.05$ ((Distribusi Normal

Berdasarkan kriteria keputusan dan uji kenormalan dari tabel 3 dan tabel 4 diketahui bahwa data dari bleep test untuk tes awal dan tes akhir pada kelompok interval training dan kelompok running circuit berdistribusi normal. Dengan demikian salah satu syarat untuk pengolahan statistik parametrik sudah tercapai. Alasannya bahwa pada uji normalitas berdasarkan hasil dari penggunaan aplikasi SPSS serie 24 memperlihatkan hasil data di atas 0.05 dari tabel hasil uji normalitas Shapirowilk. Sebenarnya normalitas tidak hanya itu, ada satu lagi yaitu uji shapiro-wilk. Penulis memilih shapiro-wilk di karenakan sampel yang dipergunakan kurang dari 30 orang dan penulis hanya menggunakan sampel penelitian berjumlah 20 orang. Sehingga penulis menggunakan data berdasarkan hasil uji normalitas pada tabel shapiro-wilk. 


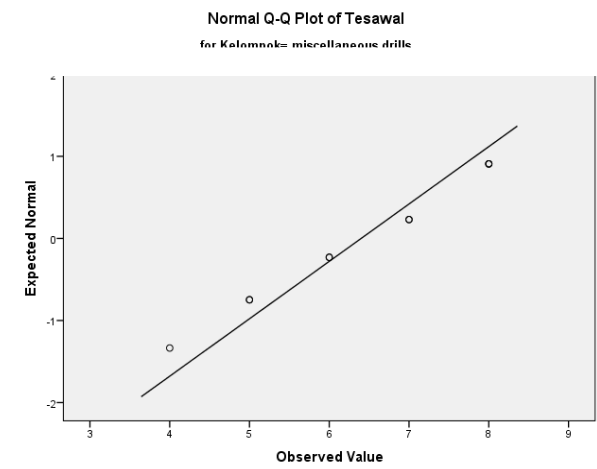

Gambar 1. Grafik Uji Normalitas Tes Awal Kelompok latihan Interval training

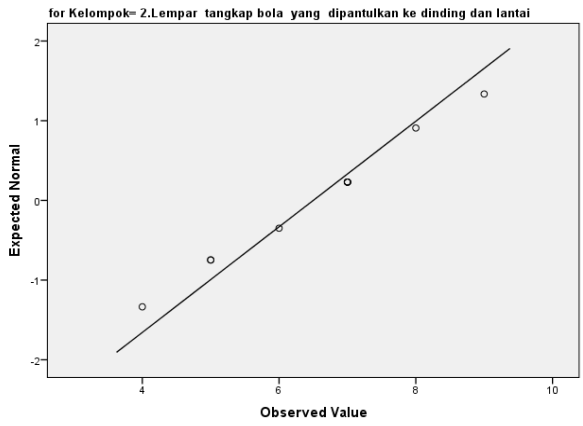

Gambar 2. Grafik Uji Normalitas Tes Awal Kelompok Running circuit

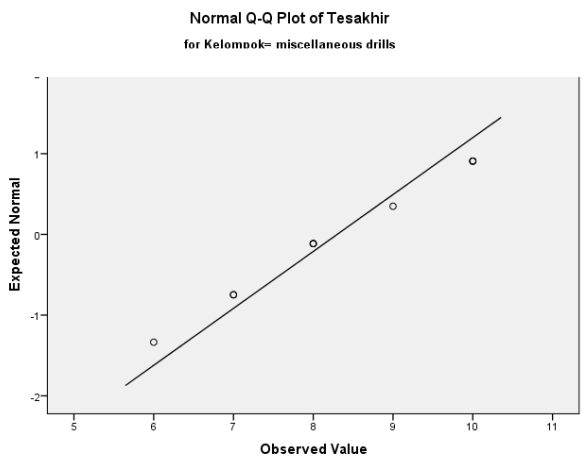

Gambar 3. Grafik 3 Uji Normalitas Tes Akhir Kelompok latihan Interval training Normal Q-Q Plot of Tesakhir

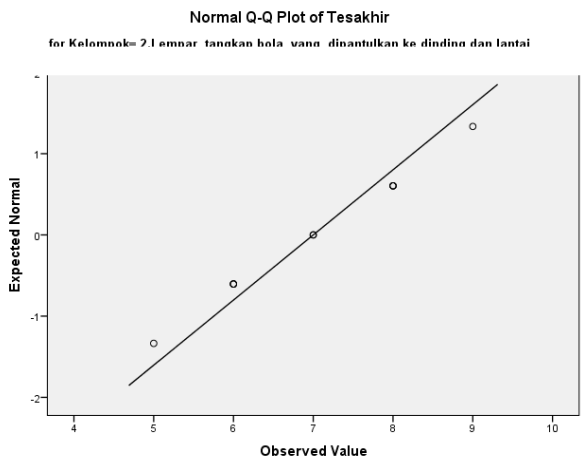

Gambar 4. Grafik Uji Normalitas Tes Akhir Kelompok Running circuit

Penjelasan grafik di atas adalah sebagai berikut :

Dari ke-empat grafik di atas terlihat garis diagonal atau garis miring dari kiri ke kanan atas. Jika suatu distribusi data normal, maka data akan tersebar di sekeliling garis, sehingga dapat disimpulkan bahwa kedua kelompok tersebut berdistribusi normal

Berdasarkan hasil analisa data tersebut, dapat disimpulkan bahwa penelitian dari kelompok latihan interval training dan kelompok latihan running circuit baik pada tes awal maupun tes akhir 
berdistribusi normal karena titik-titik data tersebar di sekitar garis dan mengikuti arah garis diagonal atau garis miring.

Uji Homogenitas

Tabel 5.

Uji Homogenitas Kelompok Interval Training dan Running Circuit

\begin{tabular}{llrrrr}
\hline & \multicolumn{2}{c}{ Test of Homogeneity of Variance } & & & \\
Levene Statistic & df1 & & df2 & \multicolumn{1}{c}{ Sig. } \\
\hline \multirow{5}{*}{ Tes awal } & Based on Mean & .000 & 1 & 18 & 1.000 \\
& Based on Median & .060 & 1 & 18 & .809 \\
& Based on Median and with & .060 & 1 & 14.931 & .810 \\
& adjusted df & .000 & 1 & 18 & 1.000 \\
& Based on trimmed mean & .267 & 1 & 18 & .612 \\
\multirow{5}{*}{ Tes akhir } & .083 & 1 & 18 & .777 \\
& Based on Mean & .083 & 1 & 16.810 & .777 \\
& Based on Median & .294 & 1 & 18 & .594 \\
\cline { 2 - 6 }
\end{tabular}

Kriteria Keputusan :

1. Nilai Sig. atau signifikansi atau nilai probabilitas $<0.05$, data berasal dari populasi yang memiliki varians tidak sama (Tidak Homogen).

2. Nilai Sig. atau signifikansi atau nilai probabilitas $>0.05$, dan berasal dari populasi yang memiliki varians sama (Homogen).

Uji Homogenitas Varians Varians (Lavene Test) :

Tes Awal

1. Berdasarkan Mean (Rata-rata) : Nilai Sig. $1.000>0.05$ (Homogen).

2. Berdasarkan Median (Tengah) : Nilai Sig. $0.809>0.05$ (Homogen)

Diketahui bahwa data tes awal bleep test, nilai probabilitas (Sig.) berdasarkan nilai rata-rata adalah $1.000>0.05$. Berdasarkan median (nilai tengah) probabilitas (Sig.) adalah $0.809>0.05$.

Tes Akhir

1. Berdasarkan Mean (Rata-rata) : Nilai Sig. $0.612>0.05$ (Homogen).

2. Berdasarkan Median (Tengah) : Nilai Sig. $0.777>0.05$ (Homogen).

Diketahui bahwa data tes akhir bleep test, nilai probabilitas (Sig.) berdasarkan nilai rata-rata adalah $0.612>0.05$. Berdasarkan median (nilai tengah) probabilitas (Sig.) adalah $0.777>0.05$.

Dapat disimpulkan bahwa data tes awal dan tes akhir bleep test memiliki varians yang sama atau homogen (Arkkelin, 2014). Dengan demikian pengolahan selanjutnya untuk dapat dilakukan dengan statistik parametrik, karena syarat dari pengolahan statistik parametrik sudah terpenuhi, yaitu normal dan homogen.

\section{Uji Hipotesis}

Langkah pertama yang akan dilakukan pada hipotesis ini uji-t menggunakan paired sample t-test untuk mengolah data hasil rata-rata tes awal dan tes akhir dari ke dua kelompok penelitian. Ujit untuk sampel berpasangan atau paired sample t-test digunakan untuk menguji perbedaan ratarata antara dua sample yang berpasangan yaitu sebelum dan sesudah mendapatkan perlakuan atau pelatihan (Everitt, Sabine Landau, 2004). Pengujian dilakukan dua sisi, dimana nilai probabilitas (Sig.) maupun dk masing-masing dibagi 2.

Tabel 6.

Uji Paired Sample t-test Kelompok Interval Training dan Running Circuit

\begin{tabular}{llcccccc}
\hline \multicolumn{2}{c}{ Kelompok Penelitian } & $\begin{array}{c}\text { Rata- } \\
\text { rata }\end{array}$ & $\begin{array}{c}\text { Std. } \\
\text { Deviasi }\end{array}$ & $\mathbf{t}$ & $\mathbf{d k}$ & $\begin{array}{c}\text { Sig. } \\
\text { (2-tailed) }\end{array}$ & Ket \\
\hline $\begin{array}{l}\text { Kelompok } \\
\text { Interval training }\end{array}$ & $\begin{array}{l}\text { Tes awal } \\
\text { dan tes } \\
\text { akhir }\end{array}$ & -1.90 & 0.56 & -10.58 & 9 & 0.000 & Signifikan \\
$\begin{array}{l}\text { Kelompok } \\
\text { Running circuit }\end{array}$ & $\begin{array}{l}\text { Tes awal } \\
\text { dan tes } \\
\text { akhir }\end{array}$ & -0.50 & 0.52 & -3.00 & 9 & 0.015 & Signifikan \\
\hline
\end{tabular}


Hipotesis 1:

$\mathrm{H} 0=$ Latihan interval training tidak memberikan pengaruh yang signifikan terhadap peningkatan

Vo2 Max pada komunitas lari running loka Kabupaten Ciamis.

$\mathrm{Ha}=$ Latihan interval training memberikan pengaruh yang signifikan terhadap Peningkatan Vo2 Max

pada komunitas lari running loka Kabupaten Ciamis.

Kriteria Keputusan :

a) Jika probabilitas (Sig.) $>0.025$ maka $\mathrm{HO}$ diterima.

b) Jika probabilitas (Sig.) $<0.025$ maka $\mathrm{HO}$ ditolak.

Diketahui nilai probabilitas (Sig.) dari bleep test untuk kelompok interval training 10/30 adalah $0.000<0.025$. Dengan demikian maka $\mathrm{HO}$ ditolak, artinya kelompok interval training memberikan pengaruh yang signifikan terhadap peningkatanVo2 Max pada komunitas lari running loka Kabupaten Ciamis

Hipotesis 2 :

$\mathrm{HO}=$ Latihan running circuit tidak memberikan pengaruh yang signifikan terhadap peningkatan

Vo2 Max pada komunitas lari running loka kab. Ciamis

$\mathrm{Ha}=$ Latihan running circuit memberikan pengaruh yang signifikan terhadap peningkatan Vo2 Max

pada komunitas lari running loka Kab. Ciamis.

Nilai probabilitas (Sig.) 0.000 dibagi 2 menjadi 0. Diketahui bleep test adalah $0.000<0.025$. Dengan demikian maka $\mathrm{HO}$ ditolak, artinya kelompok latihan running circuit memberikan pengaruh yang signifikan terhadap peningkatanVo2 Max pada komunitas lari running loka Kabupaten Ciamis. Berdasarkan analisis dan pengolahan data paired sample t-test bahwa asumsi penulis adanya pengaruh secara signifikan meskipun pengolahan data ini belum selesai dan bersifat sementara.

\section{Uji Independent Sample T-Test}

Pengolahan dan analisis data menggunakan statistika SPSS 24 selanjutnya adalah menguji perbedaan pengaruh mana yang lebih meningkat meningkat atau unggul secara signifikan atau tidak dari kelompok latihan interval training dan latihan running circuit (Everitt, Sabine Landau, 2004)setelah diberikan perlakuan selama 1.5 bulan atau sebaliknya yaitu tidak ada perbedaan di antara ke-dua kelompok penelitian tersebut. Data yang diuji adalah selisih antara tes awal dan tes akhir dari masing-masing kelompok. Pengolahan dilakukan dengan independent sample t-test dan pengujiannya dengan uji-t satu pihak, dimana nilai probabilitas (sig.) maupun derajat kebebasan tidak dibagi dua. Agar mudah dimengerti penulis mencantumkan data independent sample t-test dalam bentuk tabel 7 di bawah ini dengan memperhatikan pada kolom Sig. (2-tailed) dimana terlihat hasil yang diperoleh lebih kecil dari 0.05 .

Tabel 7.

Uji Independent Sample T-test Kelompok Interval Training dan Running Circuit

\begin{tabular}{ccccccc}
\hline Bleep test & \multicolumn{3}{c}{$\begin{array}{l}\text { Uji Lavense untuk } \\
\text { kesamaan Varians }\end{array}$} & \multicolumn{2}{c}{ T-test Untuk Kesamaan Rata-rata } & Keterangan \\
& $\mathbf{F}$ & $\mathbf{S i g}$ & $\mathbf{t}$ & $\mathbf{d k}$ & $\begin{array}{c}\text { Sig. (2- } \\
\text { tailed) }\end{array}$ & \\
\hline $\begin{array}{c}\text { Asumsi Varians } \\
\text { sama }\end{array}$ & 0.25 & 0.61 & 2.177 & 18 & 0.043 & Signifikan \\
$\begin{array}{c}\text { Asumsi Varians } \\
\text { tidak sama }\end{array}$ & & & 17.711 & 11.830 & 0.043 & Signifikan \\
\hline
\end{tabular}

Merumuskan Hipotesis

$\mathrm{Ho}=$ Tidak ada perbedaan rata-rata kelompok latihan interval training dan latihan running circuit terhadap peningkatanV02 Max terhadap peningkatan pada komunitas lari running

loka Kabupaten Ciamis.

$\mathrm{Ha}=$ Ada perbedaan rata-rata kelompok latihan interval training dan latihan running circuit 
running

circuit terhadap peningkatan Vo2 Max terhadap peningkatan pada komunitas lari loka Kabupaten Ciamis.

Menentukan t hitung

Dari output didapat nilai t hitung (Equal variance assumed) adalah 2.177

Menentukan $t$ tabel

T tabel dapat dilihat pada tabel statistik pada signifikansi $0.05: 2=0.025$ (uji dua sisi) dengan derajat kebebasan (df) n-2 atau 20-2 $=18$, hasil diperoleh untuk $t$ tabel sebesar 2.101. (Lihat pada lampiran tabel $t)$

Kriteria Pengujian

Jika $-t$ tabel $\leq t$ hitung $t$ tabel maka Ho diterima

Jika -t hitung < -t tabel atau thitung $>\mathrm{t}$ tabel maka Ho ditolak

Membuat kesimpulan

Nilai -t hitung < -t tabel $(-2.177<-2.101)$ maka Ho ditolak, jadi dapat disimpulkan bahwa ada perbedaan rata-rata peningkatanVo2 Max pada komunitas running loka Kabupaten Ciamis antara kelompok latihan latihan interval training dan latihan running circuit terhadap peningkatanVo2 Max terhadap peningkatanVo2 Max pada komunitas lari running loka Kabupaten Ciamis.

Berdasarkan hasil pengolahan dan analisis data, secara empirik kelompok latihan interval training dengan latihan running circuit terhadap peningkatanVo2 Max pada komunitas lari running loka Kabupaten Ciamis akan dijelaskan pada bagian ini. Hasil data penelitian masih harus dijelaskan karena mulai dari hasil dan pembahasan masih dalam berbentuk angka, sedangkan penjelasan deskripsi akan penulis uraikan sebagai berikut

1. Berdasarkan deskripsi data tes awal terlihat bahwa skor rata-rata antara kelompok latihan interval training dengan latihan running circuit dapat dikatakan memiliki kemampuan yang sama terbukti pada hasil tes awal bleep test tidak ada perbedaannya yang sangat besar, sehingga penulis menyimpulkan bahwa sampel penelitian dari ke dua kelompok tersebut memiliki kemampuan tes awal bleep test yang rata-rata sama yaitu rata-rata tes awal untuk kelompok interval training adalah 36.22 dan untuk kelompok running circuit adalah 38.74.

2. Berdasarkan data tes akhir terlihat bahwa skor paling tinggi diperoleh kelompok latihan interval training yaitu 48.30 sedangkan kelompok running circuit memperoleh skor 49.80 , perbedaannya hanya 1.5, namun secara garis besar ke dua kelompok penelitian tersebut adanya peningkatan terhadapVo2 Max pada komunitas running loka Kabupaten Ciamis.

3. Pembahasan selanjutnya adalah uraian hasil uji normalitas, dan berdasarkan tabel 3 dan 4 menunjukan bahwa tes awal dan tes akhir berdasarkan signifikansi lebih besar dari 0.05 artinya data yang diperoleh tes awal dan tes akhir adalah berdistribusi normal. Artinya bahwa data tersebut adalah normal sehingga pengolahan dan analisis data dapat dilanjutkan pada tahap berikut.

4. Berdasarkan grafik 1 sampai 4 penulis menjelaskan bahwa terlihat adanya garis miring ke arah sisi sebelah kanan meningkat dan adanya titik-titik yang mengitari garis miring tersebut artinya penulis berasumsi bahwa data yang diperoleh oleh kelompok interval training dan kelompok running circuit adalah berdistribusi normal, namun apabila titik-titik ini menjauh dari garis miring artinya data yang diperoleh tidak normal.

5. Berdasarkan hasil uji homogenitas pada tabel 5 menunjukan taraf signifikansi pada bagian kolom sebelah kanan terlihat angkanya di atas 0.05 yang artinya bahwa data yang ada pada kedua kelompok penelitian tersebut adalah homogen. Artinya bahwa data yang diperoleh dari sampel penelitian sebanyak 20 orang siswa SMA Negeri 3 Kabupaten Ciamis memiliki tingkat kemampuan yang rata-rata sama, sehingga langkah pengolahan data dapat dilanjutkan dengan pengujian pada pair sample t-test dan uji independent test. 
6. Berdasarkan tabel 6 terlihat signifikansi di bawah 0.05 yang artinya bahwa data ke dua kelompok penelitian (interval training dan kelompok running circuit) adanya peningkatan terhadapVo2 Max pada komunitas running loka Kabupaten Ciamis.

7. Berdasarkan tabel 7 menunjukan adanya perbedaan di antara ke dua kelompok penelitian terlihat probabilitasnya adalah $-2.177<-2.101$, namun perbedaannya tidak signifikan atau kecil, dan yang paling besar pada kolom Sig.2-tailed terlihat adanya perbedaan peningkatan antara kelompok latihan interval training dan kelompok running circuit dan yang paling besar peningkatanVo2 Max adalah kelompok interval training 10/30.

Penelitian yang dilaksanakan tidak selalu tertuju pada lingkup tujuan penelitian yang sudah jabarkan pada rumusan permasalahan penelitian dan hipotesis penelitian, namun lebih dari itu, dalam proses penelitian terkadang menemukan sesuatu hal yang baru yang dapat dijadikan bahan penelitian selanjutnya atau ada hal-hal baru yang muncul akan tetapi masih dalam lingkup penelitian itu sendiri. Untuk itu ada beberapa penemuan dalam penelitian ini yang akan diuraikan sebagai berikut:

1. Penelitian pada kelompok interval training dan kelompok running circuit ini masih menggunakan sampel penelitian siswa putra saja, namun alangkah lebih baik dapat dicoba pada sampel putri baik di lingkungan tingkatan SMA maupun pada atlet atletik namun dengan usia yang sama.

2. Penelitian ini menggunakan sampel dalam jumlah 20 orang dan itu pun dibagi 2 menjadi masing-masing kelompok berjumlah 10 orang. Penulis berasumsi bahwa jumlah sampel tersebut terlalu sedikit karena ketika di lokasi penelitian yang ada hanya 20 orang

3. Penelitian ini terbatas pada komponen kondisi fisik daya tahan umum saja, namun alangkah lebih baik dapat diteliti juga pada komponen kondisi fisik lainnya seperti power (daya ledak otot tungkai) dengan irama gerakan yang cepat dan kuat serta jumlah repetisi antara 12-15 repetisi.

4. Waktu penelitian hanya selama 1.5 bulan saja, dan penulis beranggapan masih kurang sehingga diharapkan adanya penelitian lanjutan yang mampu menggali penemuan-penemuan baru dalam waktu yang cukup lama dan dapat dikembangkan sehingga menghasilkan teori baru yang bermanfaat untuk keilmuan pada bidang ilmu kepelatihan, olahraga prestasi, maupun pada penyempurnaan program latihan.

5. Penulis berasumsi bahwa latihan interval training dan kelompok running circuit dapat diterapkan pada pelatihan cabang olahraga yang memiliki karakteristik tidak jauh berbeda, seperti pada cabang olahraga atletik, bola voli, bola basket, dan masih banyak lagi yang penting cabang olahraga yang dominan pada sistem kerja jantung dan paru-paru.

\section{KESIMPULAN}

Berdasarkan hasil analisis data yang sudah dijelaskan sebelumnya, penulis menyimpulkan bahwa latihan interval training dengan latihan running circuit berpengaruh secara signifikan terhadap peningkatanVo2 Max pada komunitas running loka Kabupaten Ciamis. Untuk lebih jelasnya kesimpulan secara keseluruhan dapat diuraikan sebagai berikut :

1. Latihan interval training memberikan pengaruh yang signifikan terhadap peningkatanVo2 Max pada komunitas lari running loka Kabupaten Ciamis.

2. Latihan running circuit memberikan pengaruh yang signifikan terhadap peningkatanVo2 Max pada komunitas lari running loka Kabupaten Ciamis.

3. Terdapat perbedaan yang signifikan antara latihan interval training dengan latihan running circuit terhadap peningkatan Vo2 Max pada komunitas lari running loka Kabupaten Ciamis.

\section{REKOMENDASI}

Sehubungan dengan hasil penelitian yang penulis lakukan, penulis mengajukan beberapa rekomendasi berdasarkan hasil penelitian adalah sebagai berikut : 
1. Penelitian ini diharapkan menjadi salah satu sumber referensi bagi peneliti lain agar penelitian pada bidang yang sama dan semakin berkembang.

2. Diharapkan bagi peneliti lain dapat menemukan kekurangan-kekurangan yang mampu menyempurnakan penelitian bentuk latihan interval training dengan running circuit.

3. Diharapkan sebagai salah satu pertimbangan bentuk latihan interval training dengan running circuit. dapat dijadikan bahan latihan kondisi fisik pada komponen daya tahan umum/kardiovaskular.

4. Diharapkan guru penjas mampu mencurahkan keilmuan yang diperoleh dari kesarjanaan olahraga agar dapat membina dan mengembangkan ilmu kepada para siswanya agar memiliki kemampuan dari segi motorik serta sebagai generasi penerus pada bidang olahraga dan pendidikan jasmani.

\section{UCAPAN TERIMAKASIH}

Ucapan terimakasih kepada pihak-pihak yang telah membantu dalam kegiatan penelitian yang dilakukan penulis, dalam hal ini adalah Komunitas Lari "Running Loka" beserta anggota yang telah membantu terlaksananya penelitian ini berjalan dengan baik.

\section{DAFTAR PUSTAKA}

Alwan, Menza Hendri, D. (2017). Faktor-Faktor Yang Mendorong Siswa MIA SMAN Mengikuti Bimbingan Belajar Luar Sekolah Di Kecamatan Telanaipura Kota Jambi. Jurnal EduFisika, 02(01), 25-35.

Arkkelin, D. (2014). Using SPSS to Understand Research and Data Analysis.

Armstrong, N. (2011). Endurance Training and Elite Young Athletes Endurance Training and Elite Young Athletes. Medicine and Sport Science, 56(November 2014), 59-83.

https://doi.org/10.1159/000320633

Astuti, R. D. (2019). Survei Daya TahanVo2 Max pada Atlet Karate Lemkari Sulawesi Selatan. Universitas Negeri Makassar.

Bădicu, G., \& Lorand Balint. (2016). The importance sports activities have over the quality of life in the adult population. Journal of Social Sciences Research, 10(May), 2003-2006. https://doi.org/10.24297/jssr.v10i1.6601

Bird, S. P., Tarpenning, K. M., \& Marino, F. E. (2005). Programmes to Enhance A Review of the Acute Programme Variables. Sports Medicine, 35(May 2014), 841-851. https://doi.org/10.2165/00007256-200535100-00002

Bruno, P., Smirmaul, C., Bertucci, D. R., \& Inaian, P. (2013). Is the VO 2 max that we measure really maximal ? Frontiers in Physiology, 4(August), 10-13. https://doi.org/10.3389/fphys.2013.00203

Cade, W. T., Bohnert, K. L., Reeds, D. N., Peterson, L. R., Bittel, A. J., Bashir, A., ... Taylor, C. L. (2018). Peak oxygen uptake ( VO 2peak ) across childhood, adolescence and young adulthood in Barth syndrome : Data from cross-sectional and longitudinal studies. Journal.Pone, 1-12.

Cheng, J., Chiu, C., \& Su, T. (2019). Training and Evaluation of Human Cardiorespiratory Endurance Based on a Fuzzy Algorithm. International Journal of Environmental Research and Public Health, 16(2390), 1-20. https://doi.org/10.3390/ijerph16132390 
Durstine, J. L., Gordon, B., Wang, Z., \& Luo, X. (2015). Chronic disease and the link to physical activity. Journal of Sport and Health Science, 2(1), 3-11.

https://doi.org/10.1016/j.jshs.2012.07.009

Everitt, Sabine Landau, B. S. (2004). A Handbook of Statistical Analyses using SPSS. New York: Chapman \& Hall/CRC Press LLC No.

Fajar Agni Fauzan, Agus Rusdiana, Y. R. (2016). Pengembangan Software Bleep Tes Tim Untuk Mengukur Vo2 Max. Jurnal Terapan IImu Keolahragaan, 01(01), 1-5.

Firmansyah, H. (2017). Hubungan Antara aspek Fisik dan Psikologis Studi pada Atlet Senam Artistik Putra Jawa Barat. Humanitas, 14(1), 78-89.

Gunawan, S., Millah, H., \& Hartadji, R. H. (2017). Hubungan antara Kadar Haemoglobin dengan KapasitasVo2 Max Pemain Sepak Bola Unsil United. Jurnal Siliwangi Seri Pendidikan, 3(1), 173-178.

Hottenrott, K., Ludyga, S., \& Schulze, S. (2012). Effects of high intensity training and continuous endurance training on aerobic capacity and body composition in recreationally active runners. (C) Journal of Sports Science and Medicine, (June), 483-488.

Hulke, S., \& Phatak, M. S. (2015). Cardiorespiratory response to aerobic exercise programs with different intensity : 20 weeks longitudinal study. Journal of Research in Medical Sciences, (July 2012), 649-655.

Igwenagu, C. (2016). Fundamentals of research methodology and data collection. N.

Junaidi. (2018). Biomotor Ability Profile of Indonesian Male Rugby Athletes For Asian Games 2018. Advances in Health Science Research, 12(Isphe), 67-71.

Lambert, M. I., Viljoen, W., Bosch, A., Pearce, A. J., \& Sayers, M. (2005). The Olympic Textbook of Medicine in Sport. (Schwellnus., Ed.) (1st editio). Blackwell Publishing.

Lugina Aditia , Badruzaman, Sandey Tantra Paramitha, J. (2018). Perbandingan Hasil TesVo2 Max Atlet Renang Menggunakan Williams Swimming Beep Test dan Bleep Test. Jurnal Terapan IImu Keolahragaan, 3(May 2019), 53-56. https://doi.org/10.17509/jtikor.v3i1.8933

Machali, I. (2016). Statistik Itu Mudah, Menggunakan SPSS Sebagai Alat Bantu Statistik. (Z. Arifin, Ed.). Yogyakarta: Lembaga Ladang Kata Kampung Basen 388 A Kotagede Yogyakarta.

Morici, G., Gruttad'Auria, C. I., Baiamonte, P., Mazzuca, E., Castrogiovanni, A., \& Maria R. Bonsignore. (2016). Endurance training : is it bad for you ? ERS, 12(2), 140-147. https://doi.org/10.1183/20734735.007016

Nystoriak, M. A., \& Bhatnagar, A. (2018). Cardiovascular Effects and Benefits of Exercise. Frontiers in Cardiovascular Medicine |, 5(September), 1-11. https://doi.org/10.3389/fcvm.2018.00135

Olstad, B. H., Bjørlykke, V., \& Olstad, D. S. (2019). Maximal Heart Rate for Swimmers, 1(235), 1-12. 
Pageaux, B., \& Lepers, R. (2018). The effects of mental fatigue on sport-related performance. Sport and the Brain: The Science of Preparing, Enduring and Winning, Part C (1st ed.). Canada, France: Elsevier B.V. https://doi.org/10.1016/bs.pbr.2018.10.004

Paradisis, G. P., Zacharogiannis, E., Mandila, D., \& Smirtiotou, A. (2014). Multi-Stage 20-m Shuttle Run Fitness Test, Maximal Oxygen Uptake and Velocity at Maximal Oxygen Uptake. Journal of Human Kinetics, 41, 81-87. https://doi.org/10.2478/hukin-2014-0035

Rahmad, H. A. (2016). Pengaruh Penerapan Daya Tahan Kardiovaskuler ( Vo 2 Max ) Dalam Permainan Sepakbola Ps Bina Utama, 1(2), 1-10.

Salin, K., Auer, S. K., Rey, B., Selman, C., \& Metcalfe, N. B. (2015). Variation in the link between oxygen consumption and ATP production, and its relevance for animal performance. Proceeding $B, 1-9$.

Scribbans, T. D., Vecsey, S., Hankinson, P. B., Foster, W. S., \& Gurd, B. J. (2016). The Effect of Training Intensity on VO 2 max in Young Healthy Adults : A Meta-Regression and MetaAnalysis. International Journal of Exercise Science, 9(2), 230-247.

Tanja C. Roy, Barbara A. Springer, Vancil McNult, N. L. B. (2010). Physical Fitness. Military Medicine, 175, 14-20.

Tirtawirya, D. (2019). The Eight-Weeks Physical Exercise Program In Maintaining Power On Taekwondo Athletes In The Competition Period. 2nd International Conference on Sports Sciences and Health 2018 (ICSSH 2018) The, 7(Icssh 2018), 54-58.

WHO. (2018). Global action plan on physical activity 2018-2030.

Rustiawan, H., Sugiawardana, R., \& Nurzaman, M. (2019). Functional movement screen (fms) sebagai tes mobilitas, keseimbangan, dan stabilitas atlet pasca cedera. Jurnal Wahana Pendidikan, 6(2), 1-9. 